\title{
Static and dynamic evaluation of wind potential in the Kara region of Togo using artificial neural networks
}

\author{
Arafat FOUSSENI ${ }^{1}$, Mawugno Koffi KODJO ${ }^{2}$, Assiongbon ADANLETE ADJANOH ${ }^{1}$ \\ ${ }^{1}$ University of Kara, Togo \\ 2 University of Lomé, Togo
}

\begin{abstract}
Togo's energy situation is characterized by a low rate of access to electricity $(38.07 \%$ in 2017). In the Kara region, there is certainly a wind potential whose study is necessary for the production of electricity. Thus, from the data recorded each day at intervals of one hour, we used Weibull distribution to evaluate the wind energy potential at $10 \mathrm{~m}$ and then at $25 \mathrm{~m}, 50 \mathrm{~m}, 75 \mathrm{~m}$ and $100 \mathrm{~m}$. However, the promotion of this source requires not only the knowledge of its potential but also the evolution of its quantity over time because in reality wind energy is confronted with the random nature of the wind. Thus, for the prediction of the wind potential in the region of Kara, we used artificial neural networks. The neural architecture used is a multilayer perceptron with a single neuron under the hidden layer whose activation function is a sigmoid function while the output layer uses a linear function. The prediction results obtained with an average squared error of 0.005 and a correlation of 0.96 show that the prediction results using this tool are acceptable and can be generalized under the same conditions on other sites. The evaluation of the wind potential in the region of Kara has enabled us to determine the amount of total energy available in the wind at different altitudes. Through the average values of wind speeds determined, we could make an optimal choice of wind turbine to convert this kinetic energy of the wind into electrical energy.
\end{abstract}

Keywords: Wind power, Weibull distribution, Artificial Neural Networks.

\section{Introduction}

Through improvement of technologies in recent years, wind power generation has reached a high level of technological maturity and industrial reliability [1]. However, the major problem with this energy is the high variability of its production due to the random nature of its source which is wind. The choice of wind turbines and the height of their mast therefore requires a prior determination of the wind potential. In this study, we will present the results and discuss the static assessment of wind potential in the Kara region after presenting the methodology and data used.

\section{Methodology}

Evaluating the wind potential of a site requires a rigorous scientific approach. This approach requires not only the meteorological data and the determination of the mathematical function used to approximate the histogram of wind speed frequencies. 


\section{Meteorological data collection}

The Kara region is one of the five regions of Togo. It consists of seven prefectures: Assoli. Bassar, Binah, Dankpen, Doufelgou, Keran and Kozah. Wind characteristics must be known in order to assess the wind potential of a site. These characteristics are mainly wind speed and direction. To these two can be added ambient temperature, pressure, relative humidity.

\section{Statical representation of the information}

When wind data information is available, it can be represented in the form of a histogram. The histogram illustrates the variation in the relative frequency of wind speeds. If the wind speed intervals are decreasing, the limit of the histogram is a probability density function [2]. However, it is difficult to manipulate the data set for a wind speed frequency distribution. For theoretical considerations, it is more appropriate to approach the wind speed frequency histogram by a continuous mathematical function than by a discrete table of values.

According to the literature, several models are available to model the wind speed distribution [3]. A Gaussian or Rayleigh distribution function is not always adequate in the case of wind speeds [4]. According to GUMBEL J.E [5], a better solution is to use the Weibull distribution [6]. Through In TROEN et al [7], the Weibull distribution is currently a standard for the representation of wind site climatology. The advantage of this representation is that the mean annual production of a given wind turbine can be quickly determined by knowing the Weibull characteristic of the site and the power curve of the wind turbine. as detailed in [7], [8].

\section{Weibull distribution}

The Weibull function can be described by two or three parameters. Due to its advantages highlighted by JUSTUS [9], [10] and to wind industry standards, we use the two-parameter Weibull function as described by TROEN et al [7]. Its mathematical expression is given by equation (1):

$$
f(v)=\left(\frac{k}{A}\right)\left(\frac{v}{A}\right)^{k-1} \exp \left(\frac{v}{A}\right)^{k}
$$

Where:

- $f(v)$ is the probability density and represents the frequency distribution of the velocities;

- $A(\mathrm{~m} / \mathrm{s})$ is the Weibull scale parameter that provides information on the average wind speed characteristic of the site; it is the value of the speed for which the Weibull function admits a maximum;

- $\quad k$ (without unit) is the Weibull form factor. representative of the asymmetry of the function; it indicates the more or less pointed character of the distribution.

For $\mathrm{k}=1$, we obtain an exponential law [4]. The Rayleigh distribution for $\mathrm{k}=2$ is only a special case of the Weibull distribution [12]. The approximation of a Gaussian distribution is obtained for $\mathrm{k}=3.6$.

\section{Hybrid Weibull distribution}

The Weibull hybrid distribution is used at sites where the frequency of calm winds is relatively high [9]. Indeed, this rather significant proportion of calm winds cannot be neglected, as the $k$ factor is close to the value 1, thus representing an exponential distribution. Equation

(2) gives us the expression of the Weibull hybrid distribution:

$$
f(v)=\left\{\begin{array}{c}
F_{0} \text { pour } v<1 \\
\left(1-F_{0}\right)\left(\frac{k}{A}\right)\left(\frac{v}{A}\right)^{k-1} \exp \left(-\frac{v}{A}\right)^{k} \text { pour } v \geq 1
\end{array}\right.
$$

$F_{o}$ represents the frequency of calm speeds. which is determined from wind data. 


\section{Available kinetic power}

The available kinetic power in the wind is given by [2], [12], [13] through equation (3)

$$
P_{d}=\frac{1}{2} \rho_{a} S v_{m}^{3}
$$

Where $P_{d}$ is the available kinetic power in the wind, $\rho_{a}$ is the air density. $S$ is the area swept by the blades and $v_{m}$ is the average wind speed upstream of the blades.

\section{Recoverable power}

It is impossible to transform all the kinetic power available in the wind into mechanical power by means of a wind turbine. That would have meant zero speed just behind the rotor. BETZ has shown [14-15] that there is an optimal wind speed behind the rotor so that there is maximum power extracted from the wind which then gives a maximum power coefficient $C_{p}$. The recoverable power is:

$$
P_{r}=C_{p} P_{d}
$$

$C_{p}=\frac{16}{27}$ for the maximum power coefficient according to Betz [14]. [15]. In practice, $0.35 \leq C_{p}$ $\leq 0.45$ according to A.W. Manyonge et al [16].

\section{Vertical extrapolation}

Wind speed can be extrapolated vertically by a logarithmic law [17].

$$
v(z)=v_{10}\left(\frac{\ln \left(\frac{z}{z_{o}}\right)}{\ln \left(\frac{10}{z_{o}}\right)}\right)
$$

where $v(z)$ is the wind speed at altitude $z . V_{10}$ is the wind speed at $10 \mathrm{~m} . Z_{0}$ is the site roughness.

\section{Wind speed forecasting techniques and extension to power forecasting}

There are two main approaches to simulating the behaviour of the wind field at a site. These are the physical and statistical approaches. So-called "physical" models are based on considerations of the physics of the atmosphere and lead to a Numerical Weather Prediction (NWP). NWP models [18] (for an introduction to NWP models) are suitable for forecasts ranging from several hours to several days. The HIRLAM (Hight Resolution Local Area Modelling). [19] and the CFD (Computational Wind Dynamics) model are the main examples. When dealing with short forecast horizons (minutes to hours), the use of statistical methods is more advisable [20]. Models using these approaches are usually based on time series analysis. The simplest of these is the autoregressive (AR) model: an nth-order AR is a model in which the future value is obtained to within one noise (error) as a linear combination of the last $\mathrm{n}$ measured values. To model different weather series [21] such as monthly precipitation [22], annual flow [23] and many other applications [24]; their generalization ARMA (or ARIMA). [25-26] has been used. Kalman filter methods [27]. Markov chain tools [28] and wavelets [29] are also time series based approaches applied to wind speed data. However all approaches that directly describe the stochastic dynamics of the amplitude face problems related to the non-Gaussian nature of its statistics and the presence of seasonal effects [20]. Other more recent techniques, based on artificial intelligence have been considered in the context of wind resource forecasting. Black-box models would also allow non-linear processes to be modelled, unlike classical linear methods. Following the studies of Cadenas et al [30], who focused their comparison on the structure of the network, they concluded that a 2-layer network with 2 neurons on the input layer and 1 on the output layer is better. The squared error obtained for this architecture is indeed $0.16 \%$. In our work. we used a twolayer perceptron and varied the number of neurons under the hidden layer. The activation function of the latter is sigmoid. At the output, the activation function is kept always linear. 
Wind speed $(\mathrm{v}(\mathrm{t}-1))$, temperature $(\mathrm{T}(\mathrm{t}-1))$, pressure $(\mathrm{P}(\mathrm{t}-1))$, relative humidity $(\mathrm{RH}(\mathrm{t}-1))$ all at time $\mathrm{t}-1$, velocity $(\mathrm{v}(\mathrm{t}-2))$ at time $\mathrm{t}-2$ are the input variables of the model. The output is of course the wind speed $(\mathrm{v}(\mathrm{t}))$ at time t. The different configurations are presented in the table below.

Table 1. Presentation of the different configurations of the prediction models

\begin{tabular}{|c|c|c|}
\hline Configurations & Input & Output \\
\hline 1 & $\mathrm{~T}(\mathrm{t}-1), \mathrm{P}(\mathrm{t}-1), \mathrm{RH}(\mathrm{t}-1), \mathrm{v}(\mathrm{t}-1)$ & $\mathrm{V}(\mathrm{t})$ \\
\hline 2 & $\mathrm{~T}(\mathrm{t}-2), \mathrm{P}(\mathrm{t}-2), \mathrm{RH}(\mathrm{t}-2), \mathrm{v}(\mathrm{t}-2)$ & $\mathrm{V}(\mathrm{t})$ \\
\hline 3 & $\mathrm{~T}(\mathrm{t}-1), \mathrm{P}(\mathrm{t}-1), \mathrm{RH}(\mathrm{t}-1), \mathrm{v}(\mathrm{t}-2)$ & $\mathrm{V}(\mathrm{t})$ \\
\hline
\end{tabular}

\section{Results. analysis and discussion}

\section{Choosing which Weibull distribution to use}

The analysis of the wind frequency histogram (Figure 1) reveals that cool and moderate winds are quite frequent $(98.70 \%)$. Calm winds, on the other hand are less frequent $(1.30 \%)$. It is therefore more practical to use the classical Weibull distribution to assess the wind potential in the Kara region as it would better reflect the wind statistics in the Kara region.

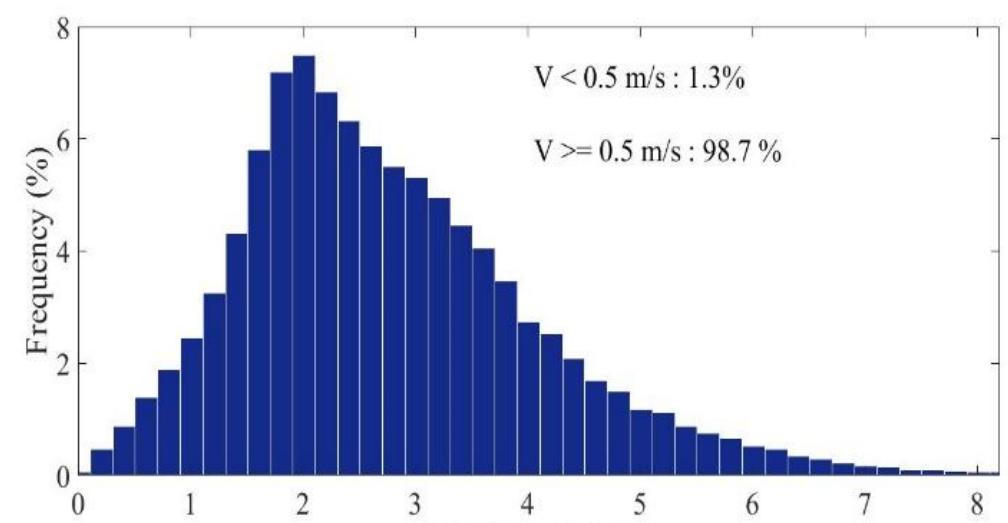

Figure 1. Fredudened histogram

\section{Frequency distribution of wind speeds}

Figure 2 is a frequency distribution. As the velocity classes are sufficiently narrow, we had represented in red through equation 1 the Weibull probability density function which is a probability law in the form of an integral. The coefficients 3.15 and 2.16 are respectively the scale parameter and the Weibull form factor. The median of $2.58 \mathrm{~m} / \mathrm{s}$ reflects that the wind thus blows at less than $2.58 \mathrm{~m} / \mathrm{s}$ half the speed of the wind of the time and at more than $2.58 \mathrm{~m} / \mathrm{s}$ during the other half. 


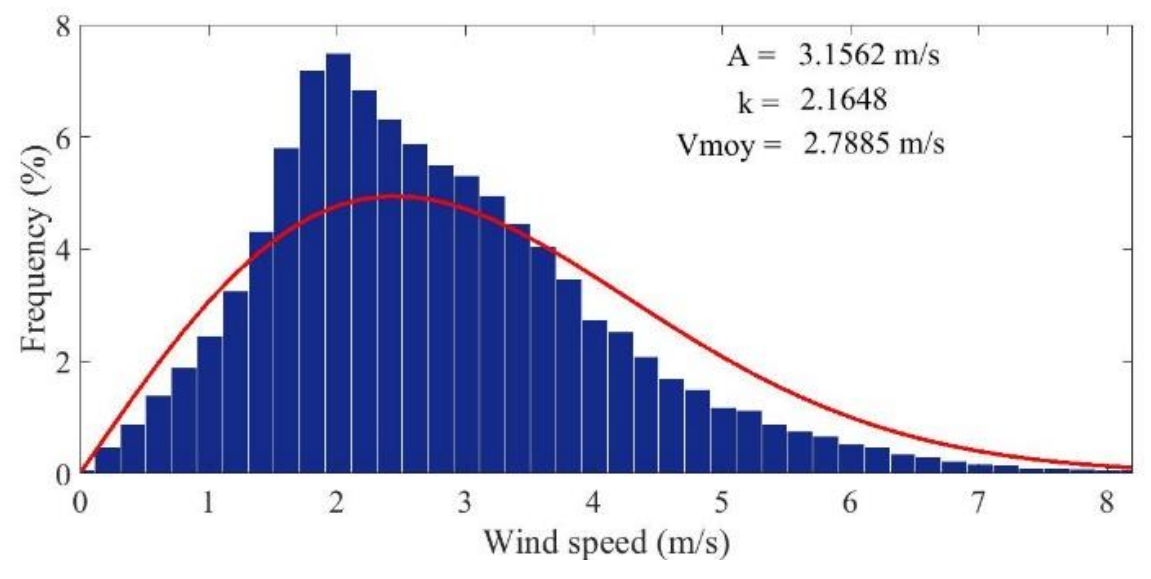

Figure 2. Weibul probability density

\section{Static evaluation of wind potential using the conventional Weibull distribution at 10 metres}

The curve in Figure 3 represents the variation of the total energy available in the wind and the maximum recoverable energy at $10 \mathrm{~m}$ as a function of wind speed. These curves were obtained using equations (3) and (4).

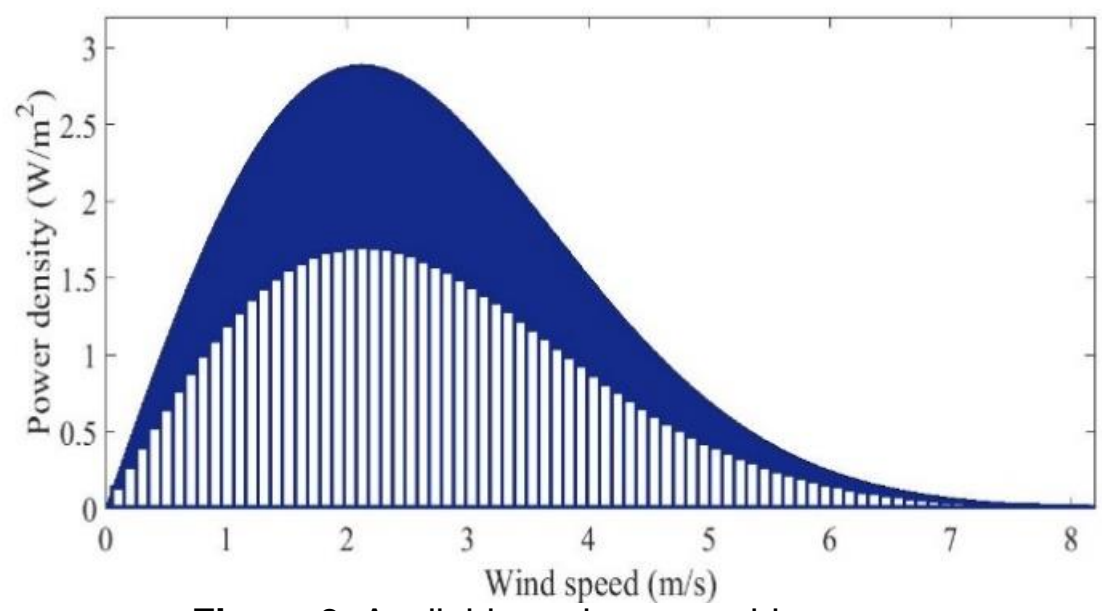

Figure 3. Available and recoverable power

On Figure 3. two main parts can be distinguished. Firstly, the extremities for which the power is almost zero. In reality, for speeds below $1 \mathrm{~m} / \mathrm{s}$ this is due not only to the scarcity of calm winds but also to the fact that their energy content is very low; on the other hand, for speeds above $5 \mathrm{~m} / \mathrm{s}$ the cause is solely due to the low frequency of strong winds. Secondly, for moderate winds with speeds between $1 \mathrm{~m} / \mathrm{s}$ and $5 \mathrm{~m} / \mathrm{s}$, the value of the total power available is not negligible. However, at an altitude of $10 \mathrm{~m}$, the total energy available in the wind is low. Moreover, at this height, the wind is often slowed down by obstacles. In order to make optimal use of wind energy in the Kara region, we therefore need to get more wind at higher altitudes.

\section{Extrapolation of results to different altitudes}

Using equation (5). the wind speed data were then extrapolated to other heights. 


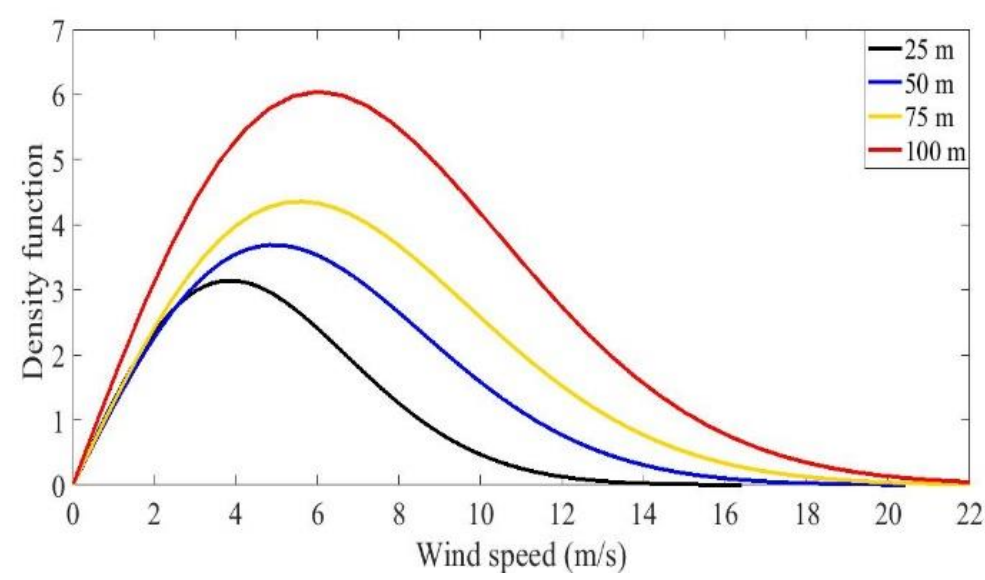

Figure 4. Wind speed distribution function at different altitudes

Analysis of Figure 4 reveals that as one moves upwards. the amplitude of the density curve increases and is shifted to the right. This phenomenon is due to an increase in the number of high wind speeds and a decrease in the number of low wind speeds resulting in an increase in the average speed. Table 2 summarizes the different average values of speed, total available and recoverable power, scaling parameter and form factor at different altitudes.

Table 2. Average values of speeds and energies at different altitudes

\begin{tabular}{|c|c|c|c|c|c|}
\hline $\begin{array}{c}\text { Height } \\
(\mathbf{m})\end{array}$ & $\begin{array}{c}\text { Average } \\
\text { speed }(\mathbf{m} / \mathbf{s})\end{array}$ & $\begin{array}{c}\text { Total power } \\
\left(\mathbf{W} / \mathbf{m}^{2}\right)\end{array}$ & $\begin{array}{c}\text { Recoverable power } \\
\left(\mathbf{W} / \mathbf{m}^{2}\right)\end{array}$ & $\begin{array}{c}\text { Scale parameter } \\
\mathbf{A}(\mathbf{m} / \mathbf{s})\end{array}$ & $\begin{array}{c}\text { Form } \\
\text { factor } \mathbf{k}\end{array}$ \\
\hline 10 & 2.79 & 27.67 & 15.21 & 3.16 & 2.16 \\
\hline 25 & 4.2 & 86.64 & 51.34 & 4.74 & 2.18 \\
\hline 50 & 5.25 & 170.09 & 100.79 & 5.94 & 2.18 \\
\hline 75 & 5.87 & 237.56 & 140.78 & 6.63 & 2.18 \\
\hline 100 & 6.3 & 294.92 & 174.77 & 7.13 & 2.18 \\
\hline
\end{tabular}

\section{Dynamic evaluation of wind speed}

\section{Features of the best models in each configuration}

The characteristics of the best model in each configuration are shown in the table below. For these 3 configurations. we note that the best results are obtained with a neuron under the hidden layer.

Table 3. Characteristics of the best architecture

\begin{tabular}{|c|c|c|c|c|c|c|}
\hline Configurations & $\begin{array}{c}\text { Number } \\
\text { of } \\
\text { neurons }\end{array}$ & MSE & RMSE & MAE & $\mathbf{R}^{\mathbf{2}}$ & $\boldsymbol{\rho}$ \\
\hline 1 & 1 & 0.00538 & 0.07341 & 0.02630 & 0.90877 & 0.95851 \\
\hline 2 & 1 & 0.01036 & 0.10179 & 0.04474 & 0.75627 & 0.88440 \\
\hline
\end{tabular}




\begin{tabular}{|c|c|c|c|c|c|c|}
\hline Configurations & $\begin{array}{c}\text { Number } \\
\text { of } \\
\text { neurons }\end{array}$ & MSE & RMSE & MAE & $\mathbf{R}^{\mathbf{2}}$ & $\boldsymbol{\rho}$ \\
\hline 3 & 1 & 0.01064 & 0.10317 & 0.04506 & 0.7489 & 0.88123 \\
\hline
\end{tabular}

\section{Prediction of available and recoverable energy with the chosen model}

The best architecture is the configuration 1 with one neuron under the hidden layer. The input variables of the neural network model are wind speed $(\mathrm{v}(\mathrm{t}-1))$, temperature $(\mathrm{T}(\mathrm{t}-1))$, pressure $(\mathrm{P}(\mathrm{t}-1))$, relative humidity $(\mathrm{RH}(\mathrm{t}-1))$ all at time $\mathrm{t}-1$. The output of the model is of course the wind speed $(\mathrm{v}(\mathrm{t}))$ at time t. The prediction results are shown in the table below in which we can distinguish the square error (MSE) and its square root (RMSE), the absolute error (MAE), the coefficient of determination $\left(R^{2}\right)$ and the correlation coefficient $(\rho)$. The figures below show the superimposed curves of target (red curve) and predicted (blue curve) energies at $10 \mathrm{~m}, 25 \mathrm{~m}, 50 \mathrm{~m}, 75 \mathrm{~m}$ and $100 \mathrm{~m}$ respectively as a function of wind speed.

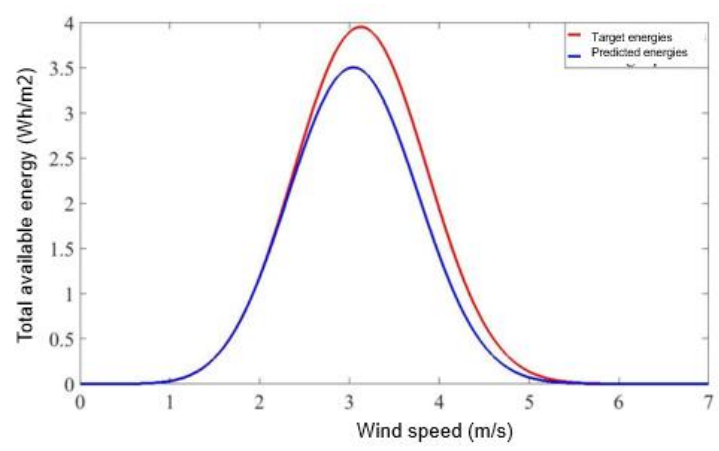

Figure 5.Target and predicted energy curves at $10 \mathrm{~m}$

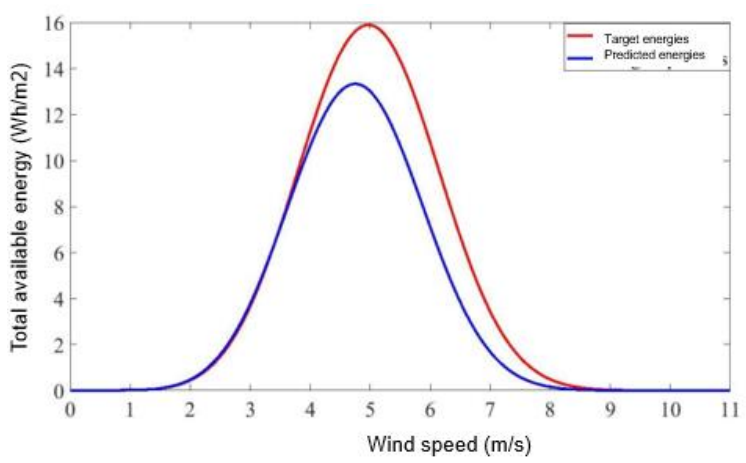

Figure 7.Target and predicted energy curves at $50 \mathrm{~m}$

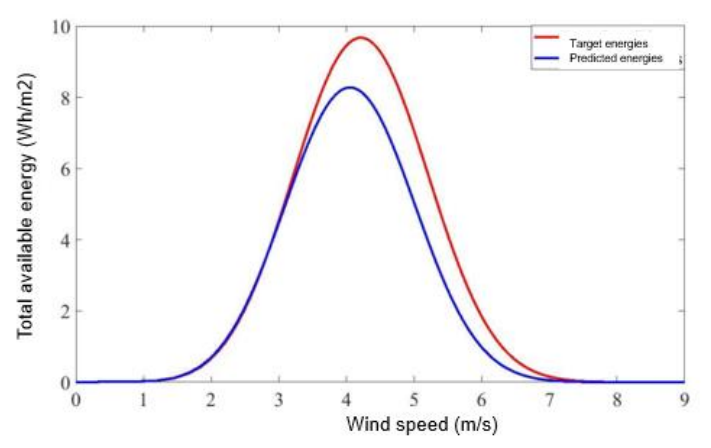

Figure 6.Target and predicted energy curves at 25m

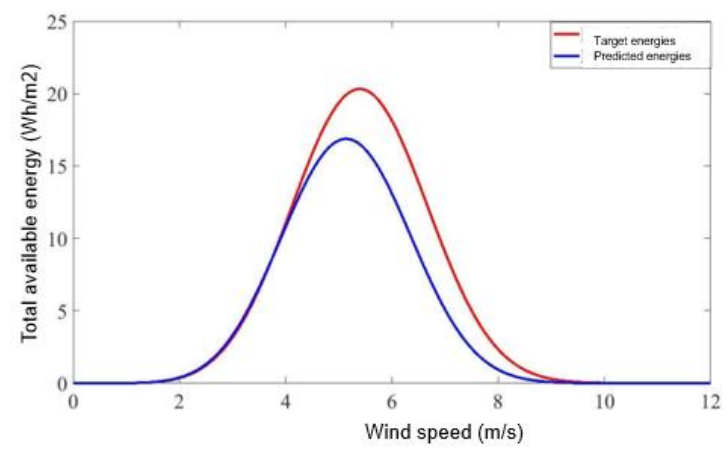

Figure 8.Target and predicted energy curves at $75 \mathrm{~m}$ 


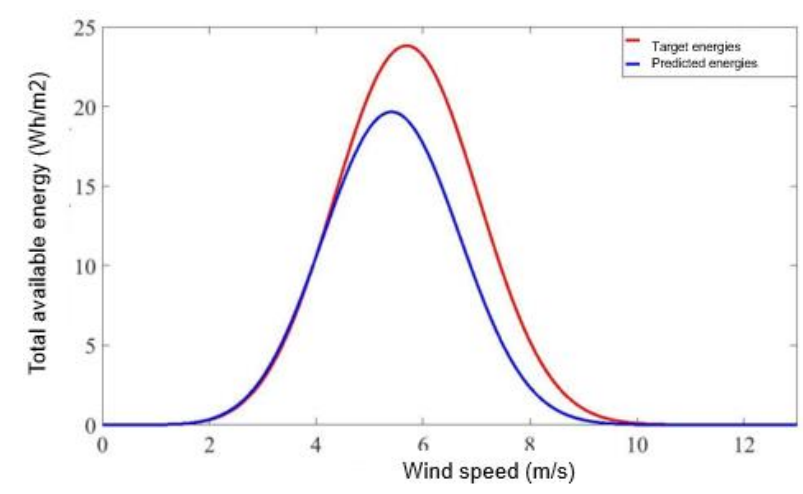

Figure 9.Target and predicted energy curves at $10 \mathrm{~m}$

The observation of the above figures reveals that each curve obtained by our neural network architecture model coincides with the energy curve available on the site. Nevertheless. a small shift between these curves is observed from $2.5 \mathrm{~m} / \mathrm{s}, 3.5 \mathrm{~m} / \mathrm{s}, 4 \mathrm{~m} / \mathrm{s}, 4.2 \mathrm{~m} / \mathrm{s}$ and $4.5 \mathrm{~m} / \mathrm{s}$ respectively at altitudes of $10 \mathrm{~m}, 25 \mathrm{~m}, 50 \mathrm{~m}, 75 \mathrm{~m}$ and $100 \mathrm{~m}$ respectively. The maximum deviation is obtained when the curves reach their maximum and begins to narrow beyond the nominal speed until a new coincidence is reached when the energy is cancelled out. The results obtained for the estimation of available and recoverable energy at $10 \mathrm{~m} .25 \mathrm{~m} .50 \mathrm{~m}$. $75 \mathrm{~m}$ and $100 \mathrm{~m}$ are given in Table below.

Table 4. Predicted energies at different altitudes

\begin{tabular}{|c|c|c|c|c|}
\cline { 2 - 5 } \multicolumn{1}{c|}{} & \multicolumn{2}{c|}{ Available energy $\left(\mathbf{W h} / \mathbf{m}^{2}\right)$} & \multicolumn{2}{c|}{ Recoverable energy $\left(\mathbf{W h} / \mathbf{m}^{2}\right)$} \\
\hline Height $\mathbf{( m}$ & Target & Prediction & Target & Prediction \\
\hline $10 \mathrm{~m}$ & 29.4362 & 27.9153 & 17.4437 & 16.5424 \\
\hline $25 \mathrm{~m}$ & 99.3230 & 94.2226 & 58.8581 & 55.8415 \\
\hline $50 \mathrm{~m}$ & 194.9986 & 185.0032 & 115.5547 & 109.6315 \\
\hline $75 \mathrm{~m}$ & 272.3616 & 258.3854 & 161.9994 & 153.1172 \\
\hline $100 \mathrm{~m}$ & 338.1195 & 320.7831 & 200.3671 & 190.0936 \\
\hline
\end{tabular}

\section{Pitch orientation}

The compass rose allows us to better appreciate the dominant wind directions. Analysis of Figure 10 reveals that there are two dominant wind directions, northeast and southwest. However, southwest, and more precisely a southward tilt of a geometric angle varying between the first and second sector (between $0^{\circ}$ and $60^{\circ}$ to the South) remains the best option for the orientation of the pales as $32 \%$ of the winds blow in this direction. This figure also supports the thesis of KODJO et al. that winds tend to generally have one or two dominant directions for which most of the energy is produced [31]. 


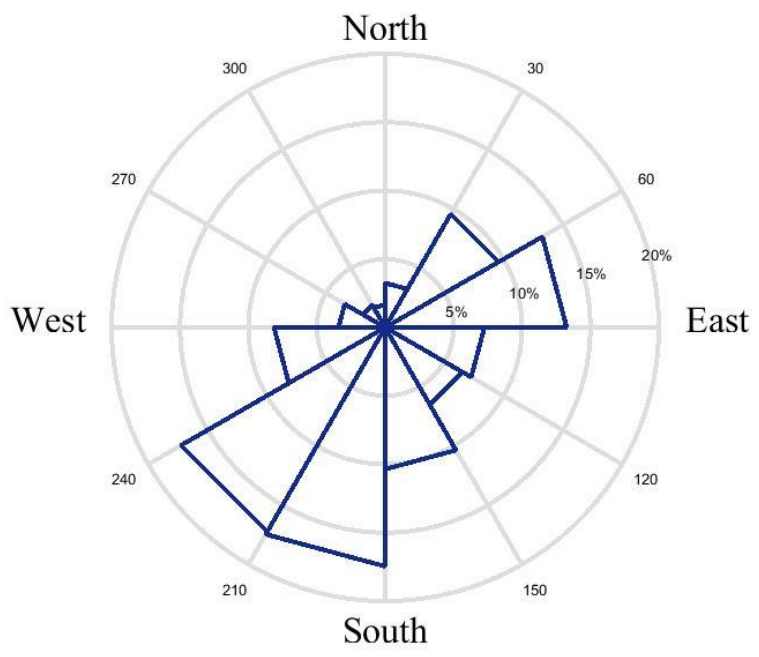

Figure 10. Compass rose

\section{Conclusion}

Prior knowledge of the wind characteristics of a site allows a better appreciation of its wind potential. In the Kara region, 20 years of data at an altitude of $10 \mathrm{~m}$ from the meteorological database of the website 'www.soda-pro.com/web-service/meteo-data/merra' were used. The wind speed data obey the Weibull distribution law with a scale parameter $A=3.16 \mathrm{~m} / \mathrm{s}$ and a form factor $k=2.18$. The study shows that the mean wind speed varies from $2.79 \mathrm{~m} / \mathrm{s}$ at $10 \mathrm{~m}$ to $6.3 \mathrm{~m} / \mathrm{s}$ at $100 \mathrm{~m}$. The average energy content of these speeds is higher at an altitude of $100 \mathrm{~m}\left(294.92 \mathrm{Wh} / \mathrm{m}^{2}\right)$. The wind rose indicates that more than $30 \%$ of the winds come from the southwest. In order to develop a much broader expertise, it would be interesting to make measurements in each prefecture of the Kara region. In this way, an atlas of the region could be established. In addition, other sites in Togo could also be studied in order to get an overview of the wind potential of the whole country. The choice of turbines should therefore be based on the characteristics of the site to better convert a large amount of the kinetic energy of the wind into electrical energy.

\section{References}

[1] de HERDE JFL, de HERDE H, GERIN A. Wind Energy: What Hybrid Energy to Fill its Defects. 2006;:pp.16.

[2] FICHAUX N. Évaluation du potentiel éolien offshore et imagerie satellitale. École des Mines de Paris, France; 2003.

[3] PHILIPPOPOULOS K, DELIGIORGI D, KARVOUNIS G. Wind Speed Distribution Modeling In The Greater Area Of Chania, Greece. International Journal of Green Energy. 2012;:9 : 174-193. https://doi.org/https://doi.org/10.1080/15435075.2011.622020

[4] PAVIA GE, O'BRIEN JJ. Weibull statistics of wind speed over the ocean. Journal of Climate and Applied Meteorology. 1986;vol. 25:pp. 1324-1332.

https://doi.org/https://doi.org/10.1175/1520-0450(1986)025<1324:WSOWSO>2.0.CO;2

[5] GUMBEL JE. Statistics of extremes. Columbia University Press. 1958;:pp. $375 .$. https://doi.org/https://doi.org/10.7312/gumb92958

[6] Weibull W. A statistical distribution function of wide applicability. Journal of Applied Mechanics. $1951 ;: n^{\circ} 18$, pp. 293-297. 
[7] TROEN I, PETERSEN E. European wind atlas. Roskilde. Risoe National Laboratory, I. 1989;.

[8] JENSEN ON, PETERSEN E, TROEN I. World climate applications programme :

extrapolation of mean wind statistics with special regard to wind energy applications. World meteorological organization. 1984;WMO/TD-No..

[9] JUSTUS C, HARGRAVES W, YALCIN A. Nationwide assessment of potential ouput from wind-powered generators. Journal of Applied Meteorology. 1976; ${ }^{\circ} 15: p p .673-678$. https://doi.org/https://doi.org/10.1175/1520-0450(1976)015<0673:NAOPOF>2.0.CO;2

[10] JUSTUS C, HARGRAVES W, MIKHAIL A, GRABER D. Methods for estimating wind speed frequency distribution. Journal of Applied Meteorology. 1978; ${ }^{\circ} 17:$ pp. 350-353. https://doi.org/https://doi.org/10.1175/1520-0450(1978)017<0350:MFEWSF>2.0.CO;2

[11] HENNESSEY J. A comparison of the Weibull and Rayleigh distributions for estimating wind power potential. Wind Engin. 1978;2:156-164.

[12] Merzouk N, Merzouk M. Estimation du Potentiel Energétique Eolien UtilisableApplication au Pompage dans les Hauts Plateaux. Revue des Energies Renouvelables. 2006; Vol. 9, N:pp. $155-163$.

[13] Sen Z, Altunkaynak A, Erdik T. Wind Velocity Vertical Extrapolation by Extended Power Law', Hindawi Publishing Corporation. Advances in Meteorology. 2012;:pp. 6. https://doi.org/https://doi.org/10.1155/2012/178623

[14] HLADIK J. Energétique Eolienne, « Chauffage éolien, Production d'électricité, Pompage. (MASSON, ed). 1984.

[15] LEGOURIERES D. Energie éolienne, théorie, conception et calcul pratique des installations. 2è Edition. (Eyrolles, ed). 1982.

[16] Manyonge A, Ochieng R, Onyango F, Shichikha J. Mathematical Modeling of Wind Turbine in a Wind Energy Conversion System: Power Coefficient Analysis. Applied Mathematical Sciences. 2012;Vol. 6, :pp. 4527 - 4536.

[17] MOLIN B. Hydrodynamique des structures offshore. 2002;:pp. 440.

[18] Kalnay E, Lord SJ, McPherson RD. Maturity of Operational Numerical Weather Prediction: Medium Range. Bulletin of the American Meteorological Society. 1998

Dec;79(12):2753-2769. https://doi.org/10.1175/1520-0477(1998)079<2753:moonwp>2.0.co;2

[19] MACHENHAUER B, HIRLAM. Technical Report 5. Copenhagen: Danish Meteorological Institute; 1988.

[20] METATLA S. Optimisation et régulation des puissances d'une éolienne à base d'une MADA. École nationale supérieure polytechnique d'Alger; 2009.

[21] Katz RW, Skaggs RH. On the Use of Autoregressive-Moving Average Processes to Model Meteorological Time Series. Monthly Weather Review. 1981 03;109(3):479-484. https://doi.org/10.1175/1520-0493(1981)109<0479:otuoam>2.0.co;2

[22] Delleur JW, Kavvas ML. Stochastic Models for Monthly Rainfall Forecasting and Synthetic Generation. Journal of Applied Meteorology. 1978 Oct;17(10):1528-1536. https://doi.org/10.1175/1520-0450(1978)017<1528:smfmrf>2.0.co;2

[23] Carlson RF, MacCormick AJA, Watts DG. Application of Linear Random Models to Four Annual Streamflow Series. Water Resources Research. 1970 08;6(4):1070-1078. https://doi.org/10.1029/wr006i004p01070

[24] Makridakis S, Wheelwright SC, McGee VE. Forecasting: Methods and Applications. 2nd. JohnWiley \& Sons; 1983.

[25] BOX P, JENKINS M. Times series analysis: forecasting and control. 1976. 
[26] Corotis RB, Sigl AB, Cohen MP. Variance Analysis of Wind Characteristics for Energy Conversion. Journal of Applied Meteorology. 1977 Nov;16(11):1149-1157.

https://doi.org/10.1175/1520-0450(1977)016<1149:vaowcf>2.0.co;2

[27] BOSSANYI E. Short-term wind prediction using Kalman filters. Wind Energy.9:1-8.

[28] Poggi P, Muselli M, Notton G, Cristofari C, Louche A. Forecasting and simulating wind speed in Corsica by using an autoregressive model. Energy Conversion and Management. 2003 Dec;44(20):3177-3196. https://doi.org/10.1016/s0196-8904(03)00108-0

[29] Kitagawa T, Nomura T. A wavelet-based method to generate artificial wind fluctuation data. Journal of Wind Engineering and Industrial Aerodynamics. 2003 06;91(7):943-964. https://doi.org/10.1016/s0167-6105(03)00037-0

[30] Cadenas E, Rivera W. Short term wind speed forecasting in La Venta, Oaxaca, México, using artificial neural networks. Renewable Energy. 2009 01;34(1):274-278. https://doi.org

[31] Kodjo M, Bédja K, Ajavon A, Lishou C. Neural networks for predictive control of the mechanism of orientation of a wind turbine. Journal des Sciences Pour l'Ingénieur . 2008;9. 